IZA DP No. 10341

Etiopathology of Europe's Sick Man:

Worker Flows in Germany, 1959-2016

Benjamin Hartung

Philip Jung

Moritz Kuhn

November 2016 


\title{
Etiopathology of Europe's Sick Man: Worker Flows in Germany, 1959-2016
}

\author{
Benjamin Hartung \\ University of Bonn \\ Philip Jung \\ TU Dortmund \\ and IZA
}

\author{
Moritz Kuhn \\ University of Bonn, \\ CEPR and IZA
}

\section{Discussion Paper No. 10341 \\ November 2016}

\author{
IZA \\ P.O. Box 7240 \\ 53072 Bonn \\ Germany \\ Phone: +49-228-3894-0 \\ Fax: +49-228-3894-180 \\ E-mail: iza@iza.org
}

\begin{abstract}
Any opinions expressed here are those of the author(s) and not those of IZA. Research published in this series may include views on policy, but the institute itself takes no institutional policy positions. The IZA research network is committed to the IZA Guiding Principles of Research Integrity.

The Institute for the Study of Labor (IZA) in Bonn is a local and virtual international research center and a place of communication between science, politics and business. IZA is an independent nonprofit organization supported by Deutsche Post Foundation. The center is associated with the University of Bonn and offers a stimulating research environment through its international network, workshops and conferences, data service, project support, research visits and doctoral program. IZA engages in (i) original and internationally competitive research in all fields of labor economics, (ii) development of policy concepts, and (iii) dissemination of research results and concepts to the interested public.
\end{abstract}

IZA Discussion Papers often represent preliminary work and are circulated to encourage discussion. Citation of such a paper should account for its provisional character. A revised version may be available directly from the author. 
IZA Discussion Paper No. 10341

November 2016

\section{ABSTRACT}

\section{Etiopathology of Europe's Sick Man: Worker Flows in Germany, 1959-2016*}

We provide new estimates on worker flow rates in and out of unemployment for Germany covering the last six decades. In the 1980s, Germany emerged as the sick man of Europe with a labor market characterized by persistently high unemployment rates. We attribute a substantial fraction of the rise in unemployment to a dramatic increase in inflow rates compared to the 1960s. Germany's recovery started in the mid-2000s after the Hartz reforms, when inflow rates persistently decreased. Comparing the German and U.S. labor market during recessions uncovers a striking similarity between the recent financial crisis in the U.S. and the German recession in the 1980s. We relate these findings to existing theories on labor market differences between the U.S. and Germany.

JEL Classification: J63, J64

Keywords: labor market dynamics, worker flows, Germany

Corresponding author:

Moritz Kuhn

Department of Economics

University of Bonn

Adenauerallee 24 - 42

53113 Bonn

Germany

E-mail: mokuhn@uni-bonn.de

* The authors gratefully acknowledge financial support by the German Research Foundation (DFG) as part of priority program DFG SPP 1764: The German Labor Market in a Globalized World. 


\section{Introduction}

In the 1980s, Germany emerged as the sick man of Europe with a labor market characterized by persistently high unemployment rates (e.g. Economist (1999)). The recent cure of the German patient has raised the question what might have been the appropriate therapy. This paper provides new estimates on worker flow rates in and out of unemployment for Germany from 1959 to 2016 to document Germany's etiopathology. Six decades of worker flow rates allow us to uncover striking similarities between recent labor market developments in Germany and past episodes from the U.S.

Based on changes in our new worker flow rates, we identify five distinct episodes in the history of the German labor market: The Wirtschaftswunder episode (1959-1973) characterized by negligible inflow rates compared to the U.S. Inflow rates were lower by a factor of 6 while outflow rates were only lower by a factor of 2 . The subsequent inflow shift episode (1973-1980) marks the beginning of the German unemployment dilemma with an unprecedented threefold increase in inflow rates in the presence of only mildly decreasing outflow rates. This inflow shift predates and at least partly conflicts with what the literature on technology-led structural change has described as "a surge in unemployment duration and a stable separation rate" Hornstein et al. (2007, p. 22). The surge in outflow rates did happen but later than commonly assumed. ${ }^{1}$ During the outflow shift period (1980-1990), outflow rates declined permanently by $50 \%$ while inflow rates increased only mildly. During the reunification episode (1990-2003), the labor market stagnated with depressed outflow rates. Finally, the episode of the German labor market miracle (2003-2016) in the aftermath of the Hartz reforms put the German labor market on the mend; inflow rates declined substantially while outflow rates increased slightly.

We demonstrate that the different episodes were also characterized by distinct business cycle reactions. While inflow rates spiked sharply and decreased quickly during the Wirtschaftswunder and labor market miracle episodes, they stayed persistently elevated during the other episodes. Both of these reactions have counterparts in the history of the U.S. labor market. When comparing the German experiences to the U.S., we uncover striking similarities between the financial crisis in the U.S. and the German recession in the 1980s. Conversely, the financial crisis in Germany looks similar to the U.S. in the 1980s.

\footnotetext{
${ }^{1}$ The IT revolution is typically believed to start in the early 1970's.
} 


\section{Data}

We use data from (archived) monthly reports of the employment agency on initial unemployment benefit claims dating back until 1959 (Amtliche Nachrichten der Bundesanstalt für Arbeit (ANBA)). ${ }^{2}$ We use this data together with unemployment rates to construct monthly in- and outflow rates from and to unemployment to provide estimates of worker flow rates covering six decades. The series cover periods with unemployment rates below 1 percent during the 1970s to periods with unemployment rates exceeding 10 percent in the 2000s.

We derive an estimate of the inflow rate $\pi_{e u}$ by dividing the number of benefit claims by the number of employed workers. We obtain monthly data from (archived) reports since 1967. ${ }^{3}$ To construct the unemployment outflow rate $\pi_{u e}$, we use the stock-flow relationship

$$
u_{t+1}=\left(1-\pi_{u e, t}\right) u_{t}+\pi_{e u, t}\left(1-u_{t}\right)
$$

where $u_{t}$ denotes the unemployment rate in period $t$ and $\pi_{e u, t}$ and $\pi_{u e, t}$ denote the in- and outflow rate in period $t$. Rearranging this relation and using information on the unemployment rate and our estimate of the inflow rate allows us to back out an estimate of the outflow rate. We add further 8 years based on annual data from 1959 to 1966. We obtain estimates for monthly flow rates by dividing annual inflows by $12 .{ }^{4}$ In the figures below, we use interpolation of the annual data to obtain smooth quarterly time series. These periods are shaded in grey and have to be interpreted with more caution. We provide the underlying data used in this paper as spreadsheet for download from the authors' webpage.

As discussed in the next section, the constructed flow rates provide estimates that closely track flow rates obtained from high-quality SIAB micro data during a period of overlap. An advantage of our new data series over worker flow rates based on micro data is that it is available immediately within the month and is easy to extend based on the approach developed in this paper. Alternative sources like the SIAB micro data become typically available with a time lag of two years and tight data protection regulation. We expect therefore that such a timely and easily available measure will be also instrumental for realtime monetary and fiscal policy decisions.

\footnotetext{
${ }^{2}$ Data from 1959 to 1967 is only reported annually.

${ }^{3}$ We base unemployment status on benefit recipient status rather than search activity. This approach is standard for the use of administrative data. We have documented in Hartung et al. (2016) that inflows to unemployment based on benefit recipient status and based on a registered unemployment, mimicking closer job search, track each other closely. We refer the interested reader to Hartung et al. (2016) for further details.

${ }^{4}$ We use the overlap between 1967 and 1976 to adjust for a small level difference.
} 


\section{Labor market episodes}

The upper part of Figure 1 compares our new estimates (red solid line) to flow rates based on SIAB data (blue dashed line) from Hartung et al. (2016). ${ }^{5}$ Inflow rates match level and cyclical movements remarkably well (top left panel). Outflow rates (top right panel) match level and trend of the micro data well. The largest discrepancy occurs during the 1980s with a level difference on average of $12 \%$ over the outflow rate from the micro data.

\footnotetext{
${ }^{5}$ Details on data and construction of worker flows rates from SIAB micro data can be found in Jung and Kuhn (2014) and Hartung et al. (2016).
} 
Figure 1: Inflow and outflow rates (1959-2016)

(a) Inflow rate (GER)

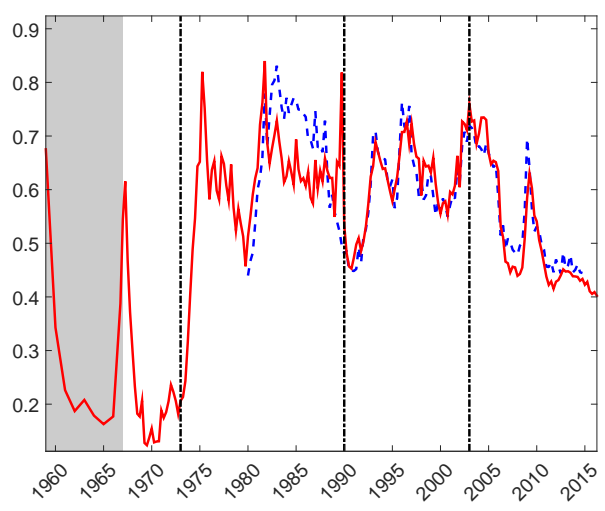

(c) Inflow rates (GER and U.S.)

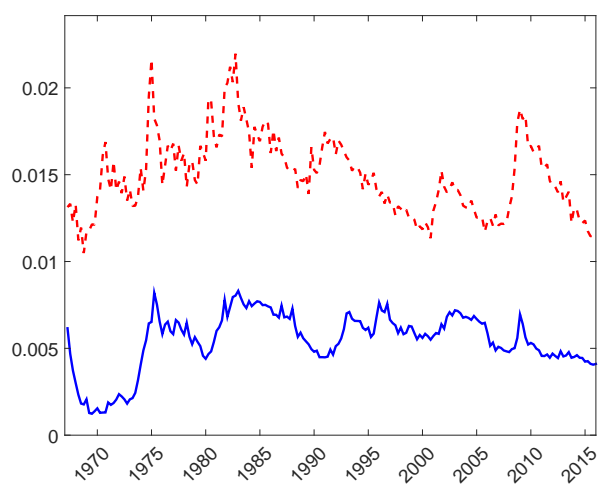

(b) Outflow rate (GER)

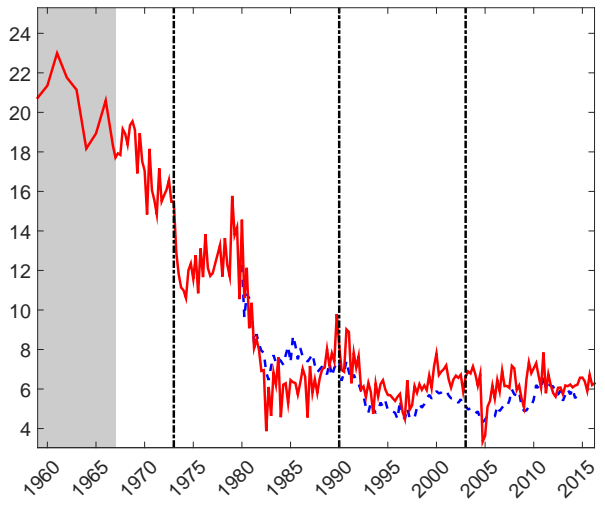

(d) Outflow rates (GER and U.S.)

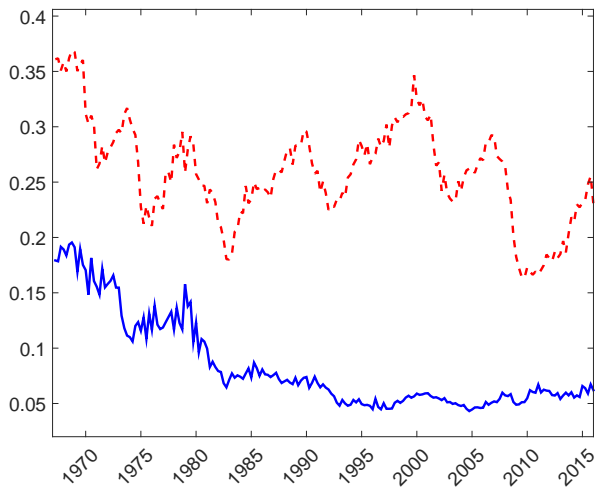

Notes: Inflow and outflow rates from and to unemployment (quarterly averages of seasonally adjusted monthly rates). Top left panel: Inflow rates from SIAB micro data (blue dashed line) and new estimates (red solid line). Top right panel: Outflow rates from SIAB micro data (blue dashed line) and new estimates (red solid line). Grey shaded area indicates period with annual data only (1959-1966). Bottom left: Estimates of inflow rates for the U.S. (dashed line) and Germany (solid line). Bottom right: Estimates of outflow rates for the U.S. (dashed line) and Germany (solid line).

To put our estimates further into perspective, we compare them to estimates for the U.S. The lower part of Figure 1 shows data for the period of overlap. For the U.S., we merge flow rates from the Bureau of Labor Statistics (BLS) going back until 1991 with flow rates from Shimer (2007) for the period 1967-1991. ${ }^{6}$

\footnotetext{
${ }^{6}$ In the period of overlap the two data series behave almost identically once the level is shifted. Accounting for time aggregation in Shimer (2007) increases flow rates; we prefer the level of the BLS data for comparison. However, the difference is minor for the discussion in this paper.
} 
Wirtschaftswunder (1959-1973): During this episode, the German real growth rates regularly exceeded 5 percent. The German labor market was characterized by very low inflow rates. While outflow rates in Germany were at about $50 \%$ of their U.S. counterpart, German inflow rates were at only $0.2 \%$ throughout that period compared to around $1.3 \%$ in the U.S. During this episode, American workers were roughly 6 times more likely to become unemployed than German workers.

Inflow shift (1973-1980) and Outflow shift (1980-1990): The two "shift" episodes lead to what constitutes the German unemployment dilemma. Our estimates scrutinize the idea formulated in among others Hornstein et al. (2007) that high unemployment rates need to be explained by "a surge in unemployment duration and a stable separation rate". While it is true that average unemployment durations increased in the 1970 s by about $25 \%$, the initial driver of the surge in unemployment rates was a threefold increase of the inflow rate during the inflow shift episode (1973-1980). Only during the outflow shift episode, outflow rates shifted permanently down to $6-7 \%$ and did not recover for the next three decades.

Reunification (1990-2003) and labor market miracle (2005-2016): The reunification episode saw flow rates remaining at their previous levels and a stagnant labor market with stubbornly high unemployment rates. The Hartz reforms and the subsequent labor market miracle revived the German patient. Since 2005 inflow rates moved down by $33 \%$ reversing part of the inflow shift; outflow rates increased slightly by $15 \%$ leading to a further decline of unemployment. Unlike most existing explanations suggest, it was the reversal of the inflow shift rather than the outflow shift that drove German unemployment rates down over the past decade. Hartung et al. (2016) explore the workings behind the German labor market miracle based on a structural labor search model and provide additional evidence for the decrease of inflow rates.

\section{Comparing German and U.S. recessions}

The different labor market episodes differed not only in mean in- and outflow rates but also with respect to their cyclical behavior. Figure 2 compares the reaction of in- and outflow rates in Germany in 1980 to the U.S. in 2007 and vice versa. The similarity of the reaction is striking. 
Figure 2: Comparing 1980 and 2007 recessions

(a) Inflows: GER-1980 and US-2007

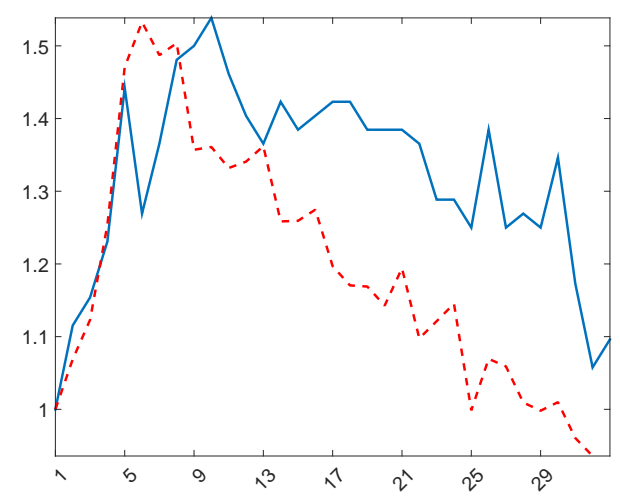

(c) Inflows: GER-2007 and US-1981

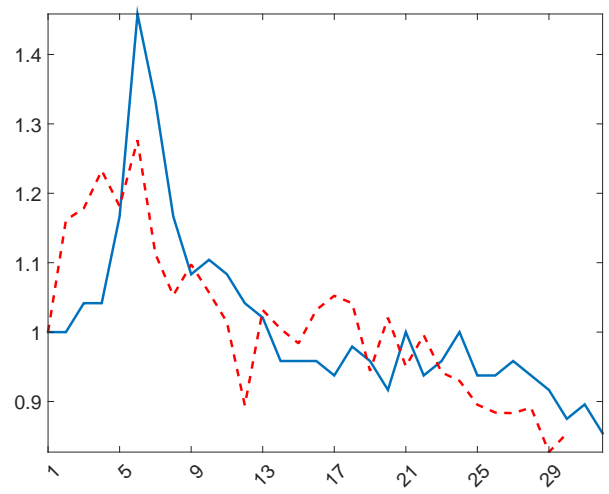

(b) Outflows: GER-1980 and US-2007

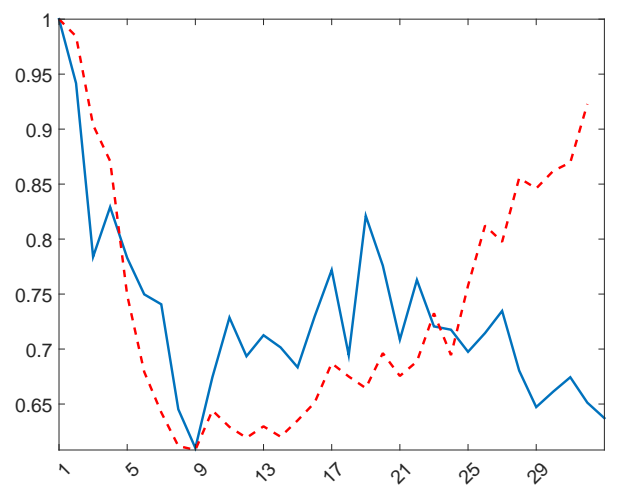

(d) Outflows: GER-2007 and US-1981

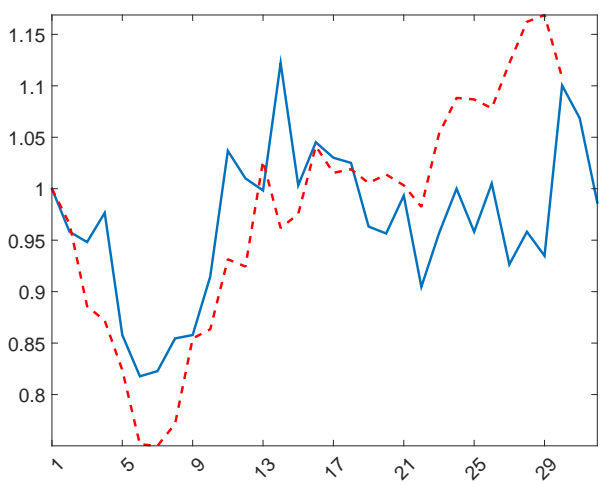

Notes: Solid line is German is the recession 1980:4 (2007:4) in the upper (lower) part, dashed line is the U.S. recession 2007:4 (1981:3) in the upper and lower part based on NBER dating. All rates are normalized to 1 at the start of the recession. A period is a quarter.

Figures $2 \mathrm{a}$ and $2 \mathrm{~b}$ show that the 1980 recession in Germany was followed by a sluggish recovery. The initial spike in inflow rates was followed by persistently high rates even 8 years later. This pattern matches closely the 2007 recession in the U.S. The U.S. inflow rate during the financial crisis spiked and remained high even 6 years after the crisis had started (Figure 2a). These patterns are in strong contrast to the U.S. in the 1980s and Germany in 2007. In 2007, the initial spike of inflows rates in Germany was followed by a quick recovery matching closely the U.S. experience of the 1980s. The evolution of German outflow rate in the 1980s is almost identical to the recent U.S. experience (Figure 2b). 


\section{Discussion and concluding remarks}

Almost 60 years of data on worker flows for Germany confirm key properties highlighted by many scholars. But the picture that emerges based on our extended dataset offers a more nuanced view on German labor market dynamics. It allows us to revisit a number of arguments that have been discussed in the literature to explain different developments in labor markets between the U.S. and Europe.

Scholars have argued that the European unemployment experience during the 1970s and 1980s is explained by the same shock as the U.S. but meeting different labor market institutions in terms of the unemployment benefit system (Ljungqvist and Sargent (1998)), wage setting (Bertola and Ichino (1995)), and employment protection (Bentolila and Bertola (1990)).

While different institutions can explain differences in average unemployment rates, Jung and Kuhn (2014) show how business cycle reactions can provide additional information about institutional differences. In this paper, we document a striking similarity in business cycle reactions between the U.S. and Germany. Some might argue these similarities are purely coincidental. Yet, the question remains why Germany as a country with more rigid labor market institutions throughout the entire period went through a large crisis in 2007 without persistent scars while the U.S. did suffer for years. If one stays within the commonshock-meets-different-institutions paradigm, the starting point is to search for changes in the institutional setting in reaction to the shock rather than to look for traditional differences across labor markets, which have largely persisted across both countries over time. The obvious candidate for such changes are unemployment benefits. The U.S. extended maximum benefit durations from 26 weeks to an unprecedented 99 weeks during Great Recession. In fact, the divergence between Germany and the U.S. reaction in Figure 2 coincides with the quarter when these extended unemployment benefits were not prolonged unexpectedly (quarter 24 is the end of the year 2013). Similarly, in 1985 Germany extended benefits for workers older than 49 years from 12 to 18 months, and a year later, benefits were further extended to a maximum of 24 months, and yet another year later to 32 months. This coincides with the point of divergence around quarter 17 in Figure 2 when inflow rates diverged. This might have contributed to the persistence of depressed outflow rates. While we observe correlations in this paper, there is an intense ongoing debate on the magnitude of the causal effect of benefit extensions in the U.S. (Hagedorn et al. (2016) and ChodorowReich and Karabarbounis (2016)). So far, no consensus has been reached. For Germany, a quantification has been given by Bender et al. (2012) using regression discontinuities. They 
find small but highly significant effects. However, Hagedorn et al. (2016) stress that these effects might be substantially downward biased because they do not include macroeconomic feedback effects on job creation. Considering the 2007 recession, it is noteworthy that the German labor market was able to recover very quickly just at a time when together with the Hartz reforms precisely the benefit extensions of the 1980s for older workers were abolished. In Hartung et al. (2016), we provide a quantitative analysis of the causal effects of the Hartz reforms on business cycle dynamics and provide further empirical evidence.

Alternatively, if one gives up the common-shock-meets-different-institutions paradigm for the recent financial crisis, one might also have to reconsider the German experience in the 1980s. It might have simply been the case that Germany was hit by a very different shock than the U.S. after all.

\section{References}

Bender, Stephan, Johannes Schmieder, and Till von Wachter, "The Effects of Extended Unemployment Insurance Over the Business Cycle: Regression Discontinuity Estimates Estimates over 20 years," Quarterly Journal of Economics, 2012.

Bentolila, Samuel and Giuseppe Bertola, "Firing costs and labour demand: how bad is eurosclerosis?," Review of Economic Studies, July 1990, 57 (3), 381-402.

Bertola, G. and A. Ichino, "Wage inequality and unemployment: United States vs. Europe," in B. Bernanke and J. Rotemberg, eds., NBER Macroeconomics Annual, Vol. 10, MIT Press, 1995.

Chodorow-Reich, G. and L. Karabarbounis, "The Limited Macroeconomic Effects of Unemployment Benefit Extensions," NBER working paper 22163, 2016.

Economist, "The sick man of the euro," June 5th, 19991999.

Hagedorn, Marcus, Fatih Karahan, Iourii Manovskii, and Kurt Mitman, "Unemployment Benefits and Unemployment in the Great Recession: The Role of Macro Effects," NBER working paper 19499, 2016.

Hartung, Benjamin, Philip Jung, and Moritz Kuhn, "What hides behind the German labor market miracle? A macroeconomic analysis," unpublished working paper, 2016. 
Hornstein, Andreas, Per Krusell, and Giovanni L Violante, "Technology-Policy Interaction in Frictional Labor Markets," Review of Economic Studies, 2007, 74 (4), 1089 1124 .

Jung, Philip and Moritz Kuhn, "Labour market institutions and worker flows: comparing Germany and the US," The Economic Journal, 2014, 124 (581), 1317-1342.

Ljungqvist, Lars and Thomas Sargent, "The eropean unemployment dilemma," Journal of Political Economy, 1998, 106.

Shimer, Robert, "Reassessing the Ins and Outs of Unemployment," NBER Working Papers 13421, National Bureau of Economic Research, Inc September 2007. 